\title{
Dominique Boutet, Histoire de la littérature française du Moyen Age
}

\section{G. Matteo Roccati}

\section{Q OpenEdition}

10 Journals

\section{Édition électronique}

URL : http://journals.openedition.org/studifrancesi/34171

DOI : 10.4000/studifrancesi.34171

ISSN : 2421-5856

Éditeur

Rosenberg \& Sellier

\section{Édition imprimée}

Date de publication : 1 novembre 2005

Pagination : 383

ISSN : 0039-2944

\section{Référence électronique}

G. Matteo Roccati, «Dominique Boutet, Histoire de la littérature française du Moyen Age », Studi Francesi [En ligne], 146 (XLIX | II) | 2005, mis en ligne le 30 novembre 2015, consulté le 18 avril 2021. URL : http://journals.openedition.org/studifrancesi/34171; DOI : https://doi.org/10.4000/studifrancesi. 34171

Ce document a été généré automatiquement le 18 avril 2021.

\section{(c)}

Studi Francesi è distribuita con Licenza Creative Commons Attribuzione - Non commerciale - Non opere derivate 4.0 Internazionale. 


\title{
Dominique Boutet, Histoire de la littérature française du Moyen Age
}

\author{
G. Matteo Roccati
}

\section{RÉFÉRENCE}

DOMINIQUE BOUTET, Histoire de la littérature française du Moyen Age, Paris, Honoré Champion («Unichamp-Essentiel», 12), 2003, pp. 208.

1 Manuel très rapide, mais s'efforçant de faire une place au «contexte historique et social», aux évolutions qui marquent la période, au «jeu des poétiques, des idéologies et de l'imaginaire» ( $4^{\mathrm{e}}$ de couverture), et d'être attentif à l'aspect pédagogique. Dans la première partie, Littérature et société (pp. 11-54), l'auteur parcourt les faits historiques marquants et l'évolution de la société, la question du plurilinguisme, l'émergence d'une culture laïque, le monde du savoir ..., puis Les conditions de la production et de la réception (oralité, écriture, «manuscriture» ...) et les idéologies et les esthétiques (cléricales, courtoises, «carnavalesques» ...). La deuxième partie, Univers littéraires (pp. 57-134), après un chapitre introductif consacré aux Poétiques et orientations de l'écriture, présente les différents Genres et formes (en organisant la matière en deux chapitres: XII ${ }^{\mathrm{e}}-\mathrm{XIII}{ }^{\mathrm{e}}$ et $\mathrm{XIV}^{\mathrm{e}}-\mathrm{XV}^{\mathrm{e}}$ ) et se termine sur quelques grands mythes (Fortune, Tristan et Lancelot, le Graal, ..., l'Orient et le paradis terrestre, la Danse Macabré). Dans la troisième partie, Petit atlas littéraire (pp. 135-187), on trouvera des séries de fiches synthétiques, résumés et définitions: Ecrivains, Euvres anonymes, Notions dominantes (formes et genres, rhétorique, termes de poétique, vie littéraire et intellectuelle), une chronologie raisonnée (en trois zones, par tiers de siècle: événements historiques, événements culturels et artistiques, textes littéraires). Les Orientations bibliographiques (pp. 189-196) et l'Index des auteurs et des œuvres cités (pp. 197-203) terminent le volume. 